Documenta \& Instrumenta

ISSN-e: 1697-3798

\title{
El delito de blasfemia en las comunicaciones entre el Tribunal de Cor- te de Madrid y el Consejo de la Inquisición
}

\author{
Carlos Pérez Fernández-Turégano ${ }^{1}$
}

Recibido: 14 de diciembre de 2016 / Aceptado: 10 de mayo de 2017

Resumen. Considerada como una injuria contra lo sagrado (Dios, la Virgen o los Santos), la blasfemia fue un delito perseguido por tres instancias jurisdiccionales distintas: la eclesiástica, la ordinaria o estatal y, por supuesto, la inquisitorial. En este trabajo se estudia en primer lugar el concepto y punición de este delito, los requisitos para que la blasfemia adquiriera la condición de herética, así como su diferenciación con otras conductas, como las proposiciones; $y$, en segundo lugar, en la parte central de este artículo, se realiza un análisis diplomático de las comunicaciones que al respecto de causas abiertas por blasfemia eran enviadas al final del proceso desde el Tribunal de Corte de Madrid al Consejo de la Inquisición. Se muestra, por su especial interés, la evolución que experimentaron estas comunicaciones escritas a lo largo del siglo XVIII.

Palabras clave. Delito de blasfemia; Tribunal de Corte de Madrid; comunicaciones; Consejo de la Inquisición.

\section{[en] The crime of blasphemy in correspondence between the Court of Ma- drid and the Inquisition Council}

\begin{abstract}
Blasphemy, considered slanderous against the sacred figures (God, the Virgen and the Saints), was a crime prosecuted by three different courts: the ecclesiastic, the ordinary and, of course, the inquisitional. In this paper, we study firstly the concept and punishment of this crime, the conditions by which blasphemy was considered heresy, as well as considering how it differed from others acts, such as "proposiciones"; and secondly, in the main part of this article, we undertake a diplomatic analysis of the correspondence relating to blasphemy trials, which were sent to the Inquisition Council by the Court of Madrid upon resolution. We place special emphasis on the way this correspondence developed over the course of the 18th century.
\end{abstract}

Keywords. Crime of blasphemy; Court of Madrid; correspondence; Inquisition Council.

Sumario. 1. El delito de blasfemia: concepto y punición. La blasfemia como pecado. 2. La consideración de la blasfemia para la Inquisición española. 3. El Tribunal de Corte de Madrid: causas de su institución. 4. Análisis diplomático de las comunicaciones del Tribunal de Corte de Madrid a la Suprema en relación con procesos por blasfemia. 5. El proceso contra Francisco Román a través de las comunicaciones del Tribunal de Corte al Consejo de la Inquisición.

1 Universidad CEU San Pablo (España)

E-mail: cperez.fcja@ceu.es 
Cómo citar: C. Pérez Fernández-Turégano, "El delito de blasfemia en las comunicaciones entre el Tribunal de Corte de Madrid y el Consejo de la Inquisición", Documenta \& Instrumenta, 15 (2017), pp. 121-143. 


\section{El delito de blasfemia: concepto y punición. La blasfemia como pecado}

Si atendemos a la primera acepción que recoge el DRAE de la palabra blasfemia, se entiende por tal la "palabra injuriosa contra Dios, la Virgen o los santos" ${ }^{2}$. Utilizada en un primer momento para designar toda injuria o difamación, y con origen etimológico en el latín blasphemia (a su vez del griego $\beta \lambda \alpha \sigma \varphi \eta \mu i ́ \alpha: ~ " B \lambda \alpha \xi^{\xi}$ ”: torpe,

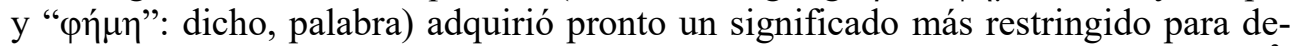
signar "una imprecación o ultraje contra Dios, los Santos o las cosas sagradas"3. Siempre otorgó la Iglesia católica a este comportamiento una enorme relevancia, como puede observarse en los escritos de San Agustín, San Jerónimo o San Gregorio Nacianceno. Según Santana:

La importancia que la blasfemia tiene en las religiones reveladas tiene su razón de ser en el lugar que en ellas ocupa la palabra, la cual debe ser utilizada para glorificar a Dios. Desde este punto de vista los comportamientos blasfemos suponen una transgresión de lo estipulado en el segundo mandamiento y una inversión del destino divino del lenguaje, provocando con ello un agravio, no tan grande a los hombres como a Dios ${ }^{4}$.

La más variada doctrina se ha manifestado en numerosas ocasiones acerca de la dificultad de distinguir entre los diferentes tipos de blasfemia, sobre todo si se trata de discernir entre una blasfemia simple y una blasfemia heretical, lo que señalaba el tribunal competente para su conocimiento, o entre una blasfemia y una proposición. Igualmente, los criterios para diferenciar una y otra varían según el autor; por ejemplo, el inquisidor Eymerich señalaba como requisito necesario de la blasfemia herética la infidelidad a la fe o la oposición directa a la confesión, de tal forma que los blasfemos heréticos serían aquellos que no creen en Dios, discrepan de él o reniegan de la $\mathrm{fe}^{5}$. Por su parte, Teruel Carralero distingue entre blasfemia simple y heretical "...y ésta en atributiva, cuando se aplica a Dios un atributo contrario a su esencia; recitativa, cuando se niega un atributo que les pertenece, e imprecativa, cuando se auguraba un mal a Dios o a los santos"6. Más recientemente, Bárbara Santiago Medina, en un interesante estudio al respecto de la distinción entre blasfemia y proposición, parte de una idea esencial: “...es necesario aclarar que, en la Edad Media, «afirmación» era sinónimo de «proposición», motivo por el cual un delito por realizar aseveraciones peligrosas contra la fe recibía la denominación de «delito de proposiciones»"

2 REAL ACADEMIA ESPAÑOLA, Diccionario de la Lengua Española, Madrid, 1992 (vigésimo primera edición), p. 298.

3 D. TERUEl CARRAlero, "El delito de blasfemia", Anuario de Derecho Penal y Ciencias Sociales, t. 4, fasc./mes 3 (1951), pp. 546-566, 553.

4 M. SANTANA MOLINA, El delito de blasfemia en el Tribunal inquisitorial de Cuenca, Alicante, 2004, p. 12.

$5 \quad M^{a}$ DEL C. FERNÁNDEZ GIMÉNEZ, La sentencia inquisitorial, Madrid, 2000, p. 84.

6 D. TERUEL CARRALERO, "El delito de blasfemia...", p. 554.

7 B. SANTIAGO MEDINA, “«De buenas o malas calidades»: Teoría y práctica de la calificación inquisitorial”, Lope de Barrientos. Seminario de Cultura, 2 (2009), pp. 305-328, 309. 
En todo caso, esta falta de precisión a la hora de delimitar una u otra clase de blasfemia fue utilizada por la Inquisición como medio de atemorizar a la población:

La operatividad del delito de herejía... se manifestó en una de sus mejores dimensiones, mediante la persecución de la blasfemia, delito de difícil delimitación en su carácter heretical, pero que por su extensión entre sus diferentes estratos sociales y por la escasa atención del Santo Oficio al establecimiento de distinciones entre ese carácter herético o la simple blasfemia, podía ser utilizado, como instrumento, para hacer sentir a la población el miedo a ser incluida, en cualquier momento, cuanto menos, en la categoría de sospechosa de la comisión de este delito, ejerciendo, a través de esta presión, el control social y la adhesión al sistema axiológico propuesto, tanto por la Iglesia como por el Estado ${ }^{8}$.

No obstante, desde las más altas instancias inquisitoriales siempre se intentó limitar el ámbito de actuación de sus tribunales a las blasfemias hereticales. Así, en las Instrucciones del inquisidor general Diego de Deza, de 1500, se señalaba textualmente que el Santo Oficio no debía intervenir en los casos en que la blasfemia era producto de la ira, y por tanto no tenía esa consideración herética: "Item, por quanto los inquisidores algunas vezes prenden por cosas livianas, no concluyentes heregia derechamente, por palabras que mas son blasfemias, que heregia, dichas con enojo, o ira, que de aquí adelante no se prenda ninguno desta qualidad, y si duda oviere, que lo consulten con los Inquisidores generales"9. Otra cosa fueron los distintos tribunales de distrito, siempre con hambre de entrar de lleno en conocer de cuantas más blasfemias mejor, para lo cual no dudaban en calificarlas como hereticales, aunque en principio no asomará ni la más mínima sospecha de herejía ni en su contenido ni por las circunstancias en que eran pronunciadas ${ }^{10}$.

Como se ha señalado, la consideración de una blasfemia como herética, o no, determinaba en un principio la jurisdicción competente para su conocimiento. Lo que produjo, en consecuencia, numerosos conflictos de jurisdicción entre los tribunales inquisitoriales, los seculares y los eclesiásticos, deseosos todos ellos de avocar a sí mismos el conocimiento de la causa y su posterior castigo, con lo que ello podía suponer desde el punto de vista monetario por las multas impuestas a los condenados. Incluso, se dio el caso de algún blasfemo juzgado varias veces por el mismo hecho por tribunales distintos. Santana Molina, citando a Lea, refiere el caso de Diego Cabeza, quien en 1620 fue condenado por blasfemo por Francisco Prieto, juez de su localidad (Manzanal, Zamora) a una multa de 40 ducados. Su delito consistió en decir a su contrincante, en el curso de una pelea, una frase similar a la siguiente: "No sé dónde podía estar Dios cuando te hizo". Sin embargo, a pesar de estar ya castigado, cuando el tribunal episcopal conoció los hechos, fue nuevamente juzgado y arrestado. No quedó ahí su peregrinaje judicial, pues en

M. SANTANA MOLINA, El delito de blasfemia..., p. 37.

9 Este texto en J. C. DOMÍNGUEZ NAFRÍA, "La «copilación» de las instrucciones inquisitoriales de Gaspar Isidro de Argüello”, Revista de la Inquisición, núm. 12 (2006), pp. 137-276, 221.

10 Durante todo el siglo XVI no varió la postura del Santo Oficio al respecto, como relata Lea: "Ya en 1535 había interpretado [la Suprema] las Instrucciones de 1500 atribuyendo las exclamaciones irreflexivas de ira a los tribunales episcopales, y en 1560 incluyó «por vida de Dios» entre las blasfemias no heréticas" (H. C. LEA, Historia de la Inquisición española, vol. II, Madrid, 1983, p. 745). 
1630 fue denunciado al tribunal del distrito inquisitorial de Valladolid, que calificó los hechos como blasfemia herética, pues de lo contrario no podía castigarla. Sin embargo, entre los inquisidores de este tribunal imperó el sentido común, pues conocedores de que habían transcurrido diez años desde la comisión del delito y de que ya había sido castigado, decidieron con buen criterio suspender la causa ${ }^{11}$.

Las penas que se imponían a los blasfemos variaron según la jurisdicción competente. Tratándose de los tribunales ordinarios, los Reyes Católicos habían establecido unas penas, en sendas leyes de 1492 y 1502, que iban desde un mes de prisión para la primera vez ${ }^{12}$, seis meses de destierro y multa de mil maravedís para la segunda, hasta la perforación de la lengua si se llegaba a una tercera condena por blasfemia $^{13}$. Felipe II, en 1566, estableció una pena de diez años de galeras para la primera condena, agravando de esta manera la condena ante la acuciante necesidad de remeros para las galeras del Mediterráneo ${ }^{14}$. Ya en el siglo XVII, en 1639, Felipe IV estableció “...la pena de diez días de cárcel y veinte mil maravedíes por la primera sentencia, treinta días de cárcel y cuarenta mil maravedíes para la segunda y cuatro años de destierro de la ciudad, conmutable por presidio o galeras según la calidad del delincuente"15.

Esta grave penalidad, propia de los tribunales ordinarios, no encontró su correlato, salvo en contadas ocasiones, en el caso de los tribunales inquisitoriales. Y es que, por regla general, en el caso de los blasfemos la Inquisición actuó con cierta moderación. Según Lea, las penas más frecuentes era abjuración de levi, aparición en un auto, mordaza, azotes y galeras, pero indica que las más graves (azotes y galeras), se reservaban para "...casos graves de blasfemia habitual de culpables de categoría social inferior". Es más, como gran parte de las blasfemias eran pronunciadas en el curso de un juego de cartas o en estado de embriaguez, no eran merecedoras más que de una simple reprensión, o de otras penas meramente nominales, cuando no de la misma absolución ${ }^{16}$.

Un claro ejemplo de la benignidad de las penas impuestas por el Santo Oficio en procesos por blasfemia, aún más tratándose de una persona de cierta categoría social, lo encontramos en la causa seguida contra Antonio Manuel de Illescas en 1753. Era éste vecino de Madrid y Armero Mayor de Su Majestad, por lo que a pesar de haber sido hallado culpable por "blasfemo heretical, y ultrajes a las Sagradas Ymagenes", abjuró de levi y fue "absuelto ad cautelam, y enterado de que por espacio de un mes hiciesse exercicios espirituales, en el convento que eligiesse, y al fin de ellos una confesión genl... y por penitens saludables que oyesse misa, y rezase el rosario todos los días observando la forma del ayuno en la proxma. cuaresma..." 17 . Es cierto que esta benevolencia se le aplicaba, como indicaba la comunicación del Tribunal de Corte a la Suprema, "atendiendo al honor de su persona, y parentela", de lo que se deduce que su condición de armero mayor del rey y su filiación contaron efectivamente a la hora de dictar sentencia; pero no es menos

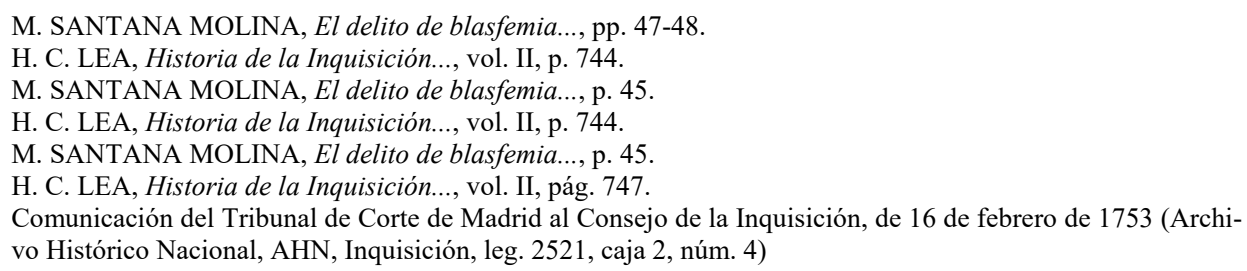


cierto que estas mismas penas (abjuración de levi, oraciones, ayuno...) constituyeron la norma general en numerosísimos procesos por blasfemia en la España Moderna.

\section{La consideración de la blasfemia para la Inquisición española}

Sea una cosa u otra, lo cierto es que la blasfemia no fue nunca centro de atención principal por parte del Santo Oficio. Hubo otras conductas (protestantes, bígamos, solicitación en confesión, por ejemplo) que sufrieron más dura represión que la simple blasfemia. En opinión de Gelabertó, nunca se estimó a los blasfemos como una amenaza peligrosísima para la ortodoxia católica: "Para la inquisición las blasfemias eran un delito menor dentro de los errores contra la fe cristiana. El Santo Oficio se ocupó de los blasfemos cuando los considerados mayores crímenes contra la fe, judaísmo y luteranismo, ya no planteaban problemas" ${ }^{18}$. En este sentido, el mismo autor se hace eco de la postura personal de Isidro San Vicente, inquisidor de Toledo, que al respecto señalaba lo siguiente: "Los blasfemos aunque reincidan muchas veces nunca vienen a ser más que levemente sospechosos y así solamente abjuren de levi" 19 .

No obstante, no conviene tampoco minusvalorar la atención que el Santo Oficio prestó a los blasfemos. Es cierto que como consecuencia de su frecuencia, de su "ritualidad", y de las circunstancias en que se pronunciaban las blasfemias, muy frecuentemente en lances de un juego de cartas o de dados, los inquisidores sabían que en general no se estaba poniendo en duda su fe. Así lo señala Bennassar:

Saben que es ritual, estereotipada, basada en una media docena de fórmulas-tipo que, a lo más, permiten algunos juegos de permutaciones. La blasfemia, que en sí es ritual, lo es también en su empleo. Puede ser la señal de la pertenencia a un grupo. No es casual que un número relativamente alto de nobles aparezca entre los blasfemos habituales. No es causal que sea jugando cuando se blasfema más veces, hasta el punto de que parece un condimento indispensable del juego del dinero. Por último, es ritual también como señal de cólera... o de desesperación $^{20}$.

Expresiones como "mal grado aya Dios", "pese a Dios", reniego a Dios" o "descreo de Dios" eran pronunciadas habitualmente y, como refleja Lea, no era posible acabar con esta práctica "...ni con la más severa legislación”"21. Este mismo autor, Henry Charles Lea, buen conocedor de la Inquisición española, define acertadamente el carácter español, tan proclive, entonces y ahora, a las blasfemias: "El español es colérico y no suele poner especial cuidado en medir las palabras cuando está poseído de un arrebato de ira; el juego es pasión casi universal, y en todos los países y épocas nada ha provocado más interjecciones y exabruptos que las alterna-

18 M. GELABERTÓ VILAGRÁN, "Legislación y justicia contra blasfemos (Cataluña, siglos XV-XVII)", Hispania Sacra, LXIV, no 130 (julio-diciembre 2012), pp. 525-564, 558.

19 Ibídem.

20 B. BENNASSAR, Inquisición española: poder político y control social, Barcelona, 1984, p. 215.

21 H. C. LEA, Historia de la Inquisición..., vol. II, p. 744. 
tivas de un juego de cartas o dados"22. Conocido es el caso, que cita Escudero, de aquel jugador de cartas que en el fragor de la partida le espetó a su contrincante: "Aunque Dios fuera tu compañero, no ganarías esta partida". Oído por alguien cercano, fue denunciado y procesado por el Santo Oficio ${ }^{23}$.

Los números de procesos abiertos por blasfemia en distintos tribunales inquisitoriales vienen a confirmar las anteriores consideraciones acerca de la atención que el Santo Oficio prestó a este delito. Así, por ejemplo, Santana resume el caso del Tribunal de Cuenca: “...de los 160 casos juzgados por blasfemias entre los siglos XVI y XVIII, penitenció a veinticinco, todos ellos entre 1560 y 1605 , reprendió a catorce, seis entre 1560 y 1600 , tres entre 1600-1700 y cinco entre 1700-1800; el resto fueron, un reconciliado, un amonestado, un advertido, un absuelto y cuatro nihil” ${ }^{24}$. En Barcelona puede apreciarse también la progresiva evolución hacia una menor persecución de esta conducta: "El desglose por siglos da el siguiente resultado: en el siglo XVI se abrieron 120 procedimientos penales (106 hombres y 14 mujeres); 102 en el XVII (97 hombres y 5 mujeres); en el siglo XVIII se recuentan 18 (16 hombres y 2 mujeres)" ${ }^{\prime 25}$.

El estudio de las causas por blasfemia en otros tribunales, algunos de cierta "enjundia" como los de Sevilla y Toledo, viene a abonar la idea de esa mitigación tanto en la represión como en la penalidad del blasfemo. González de Caldas, para el tribunal de Sevilla, indica que entre 1635 y 1699 el número de procesos seguidos tanto por blasfemias como por proposiciones fue de 96, que representaban apenas el $6,9 \%$ del total ${ }^{26}$. Bartolomé Bennassar, por su parte, además de citar el sentir de otro inquisidor del tribunal toledano acerca del escaso interés del Santo Oficio por los blasfemos: "«Algunas blasfemias y palabras mal dichas de personas groseras y bajas»", describe cómo a partir de la segunda mitad del siglo XVI ya se produce "...una ruptura brutal, un hundimiento del número de acusados, precisamente en el momento en que el delito, muy próximo, de las «proposiciones» se eleva hasta alcanzar su máximo"27. Con independencia de la distinción entre blasfemia y proposición, a la que se aludirá más adelante a la vista de su uso en las comunicaciones escritas del Tribunal de Corte de Madrid a la Suprema, autores como Blázquez o Lea confirman lo ya apuntado: la tendencia progresiva de la Inquisición a la no persecución, dicho de otro modo, a "hacer la vista gorda" con los blasfemos. Blázquez menciona, refiriéndose al tribunal de Toledo, cómo a partir del siglo XVII las blasfemias "casi desaparecen entre los delitos inquisitoriales y en concreto en Talavera transcurre casi un siglo hasta que aparece Gaspar García Tenorio, en 1649 "28. Lea concluye señalando las razones que llevaron al Santo Oficio a disminuir su "interés" por este delito: "Resulta evidente, pues, que en esta materia la actividad de la Inquisición disminuyó grandemente con el paso del tiempo, fuese

\footnotetext{
22 Ibídem, p. 743.

23 J. A. ESCUDERO, La Inquisición española: revisión y reflexiones. Lección inaugural del Curso 2000-2001, Madrid, 2000, p. 22.

24 M. SANTANA MOLINA, El delito de blasfemia..., p. 99.

25 M. GELABERTÓ, “Legislación y justicia...”, p. 558.

26 V. GONZÁLEZ DE CALDAS, ¿Judios o cristianos? El Proceso de Fe. SanctaInquisitio, Sevilla, 2000, p. 121.

27 B. BENNASSAR, Inquisición española..., pp. 209-210.

28 J. BLÁZQUEZ MIGUEL, Herejía y heterodoxia en Talavera y su antigua tierra. Procesos de la Inquisición, 1478-1820, Toledo, 1989, p. 171.
} 
por un aumento de la reverencia popular o por una creciente inclinación a no denunciar la falta" 29 .

\section{El Tribunal de Corte de Madrid: causas de su institución}

Antes de analizar el contenido y diplomática de las comunicaciones del Tribunal de Corte de Madrid a la Suprema en relación con procesos por blasfemia, conviene hacer siquiera una breve referencia a las causas que determinaron el establecimiento en Madrid de este tribunal.

Inicialmente, Madrid perteneció al distrito de la Inquisición de Toledo. El tribunal toledano enviaba a Madrid a los denominados comisarios de Corte, quienes visitaban la capital regularmente. Sin embargo, el primer embrión de lo que posteriormente sería el Tribunal de Corte, con sede en Madrid, fue el nombramiento en 1583 de Juan de Llano de Valdés como comisario del Santo Oficio en Madrid ${ }^{30}$. Dependiente del inquisidor general, y no del Tribunal de Toledo, lo cierto es que la creación de esta figura siempre causó cierto resquemor en este último tribunal, pues suponía la existencia en Madrid, por tanto junto a la Suprema, de un empleo, todavía no tribunal, que podía restar influencia y poder al tribunal toledano.

Ya en la tercera década del siglo XVII surge una nueva figura, la del inquisidor asistente en Corte, empleo que fue servido durante unos años por el licenciado Gaspar de Peralta ${ }^{31}$. En 1625, como relata Domínguez Salgado, el inquisidor general Andrés Pacheco, nombró al inquisidor de Toledo Alonso Téllez Girón como "Comisario del Santo Oficio en esta Villa de Madrid y Corte de S. Magd.". Y cuando al año siguiente el licenciado Diego Serrano fue nombrado inquisidor asistente en Corte se construían "las bases del futuro Tribunal de Corte" 32 , dependiendo directamente del Consejo ambos empleos, inquisidor de Corte y comisario.

Sin embargo, solo un año más tarde, en 1627, el inquisidor general Zapata volvió a la situación anterior, es decir, un comisario asistente en Corte, pues decidió suprimir el empleo de inquisidor asistente en Corte. Una nueva vuelta de tuerca se produjo en 1630 como consecuencia del proceso abierto contra las monjas de San Plácido, que hizo ver la necesidad de un tribunal inquisitorial propio en Madrid. No obstante, para mantener la ficción de que ese tribunal o pseudotribunal dependía de Toledo, los inquisidores de Corte “...serán nombrados como Inquisidores Apostólicos de Toledo con Asistencia en Corte, de esta forma todo quedaba dentro de una «legalidad», pareciendo, a primera vista, que dichos inquisidores dependían de Toledo, aunque la realidad fue que siempre dependieron del Inquisidor General" 33 .

Durante más de una década los miembros de este tribunal se denominaron "inquisidores del reino de Toledo para asistir en la Corte", hasta que en 1644 el inquisidor general Diego de Arce y Reinoso elevó al rey una consulta proponiendo una

29 H. C. LEA, Historia de la Inquisición..., vol. II, p. 748.

30 J. CONTRERAS, y J. P. DEDIEU, "Estructuras geográficas del Santo Oficio en España”, Historia de la Inquisición en España y América, vol. II (1993), pp. 3-47, 18, dirs. J. PÉREZ VILLANUEVA, y B. ESCANDELL BONET.

31 Ibídem.

$32 \mathrm{M}^{\mathrm{a}}$ del P. DOMÍNGUEZ SALGADO, "Inquisidores y fiscales de la Inquisición de Corte (1580-1700)", Revista de la Inquisición, nº 4 (1995), pp. 205-247, 209.

33 Ibídem, p. 210. 
solución a “...los problemas que plantea la cohabitación de dos tribunales tan cercanos como los de Madrid y Toledo, las desavenencias entre ambos, que merman la autoridad del Santo Oficio, y las dificultades de los inquisidores de Corte para imponer su autoridad en tan grande villa" ${ }^{34}$. Dicha solución consistió, pues fue aprobada por Felipe IV, en volver a la estructura inicial, mínima en todo caso, de este "tribunal": un comisario nombrado por el inquisidor general, y visitas anuales a la Villa de Madrid de los inquisidores de Toledo.

Arce y Reinoso, el mismo que había aprobado esta reducción de la estructura del tribunal madrileño, tuvo que volver sobre sus propios pasos, pues prontamente se dio cuenta de la imposibilidad material y física del tribunal de Toledo para asistir y ocuparse de todas las causas abiertas en Madrid. Por ello, a mitad de siglo, como indica Domínguez Salgado, restauró el Tribunal de Corte, "pasando a denominarse Despacho de Corte, dotándole de casas, cárceles, funcionarios con título del nuevo tribunal y de todo lo necesario para su nueva trayectoria histórica" 35 .

Se produce en este momento la consolidación de este Tribunal en Madrid, ya de manera definitiva, y aún sin una disposición legal que así lo hubiera dispuesto, con efectiva independencia del Tribunal de Toledo.

\section{Análisis diplomático de las comunicaciones del Tribunal de Corte de Ma- drid a la Suprema en relación con procesos por blasfemia}

El origen de este tipo de correspondencia documental entre el Tribunal de Corte de Madrid, y el resto de tribunales de distrito, con la Suprema, las denominadas comunicaciones, residía en la obligación que estos tribunales tenían de someter todo el aparato probatorio, antes de dictar sentencia, a una junta de asesores que debía emitir el correspondiente dictamen sin el cual los inquisidores del correspondiente tribunal no podían emitir su fallo. Indica Aguilera Barchet que la actuación de esta junta era práctica arraigada en la Inquisición española desde el primer momento, de tal forma que terminado el período de prueba se debía reunir una comisión formada por religiosos y seglares cuya misión consistía en revisar todo el proceso de principio a fin y votar sobre la inocencia o culpabilidad del procesado ${ }^{36}$. Lea ha explicado detenidamente cómo sucedía esta última fase del proceso:

Agotados así los recursos de la acusación y la defensa, se requería a la última que concluyese y se declaraba concluso el caso, si bien el fiscal podía abrirlo de nuevo si aparecían nuevas pruebas, y el acusado podía apelar como contra cualquier sentencia. Entonces estaba listo para la resolución final, pero los inquisidores no estaban autorizados para pronunciar ellos solos la sentencia. La necesidad de participación episcopal imponía la intervención de un representante del obispo de la diócesis del preso, y además se mantenía la norma de la antigua Inquisición según la cual se reunían algunos graduados en leyes y teología para deliberar y vo-

34 J. CONTRERAS y J. P. DEDIEU, “Estructuras geográficas...”, p. 20.

35 Ma del P. DOMÍNGUEZ SALGADO, "Inquisidores y fiscales...", p. 214.

36 B. AGUILERA BARCHET, "El procedimiento de la Inquisición española", en Historia de la Inquisición en España y América, vol. II, Madrid, 1993, pp. 334-558, 460-461. (dirs. J. Pérez Villanueva, y B. Escandell Bonet). 
tar con los demás. A éstos se les llamaba consultores, y ya hemos visto que se les reconocía como integrantes de la organización inquisitorial. Todo el conjunto formaba lo que se conocía como consulta de fe, de cuyas manos dependía la suerte del acusado ${ }^{37}$.

Sin embargo, esta práctica fue poco a poco desapareciendo, acentuándose, al contrario, el control y revisión por la Suprema del citado aparato probatorio. En definitiva, se trataba de controlar y fiscalizar por el Consejo de la Inquisición la actividad de los distintos tribunales inquisitoriales, los cuales estaban obligados a "...consultar y recabar el visto bueno o la decisión del Consejo, sobre todo en materia económica y procesal" "38. Juan Antonio Llorente ha descrito así este cambio en la tramitación última de las causas, iniciado ya en las Instrucciones de Torquemada de 1488 que resumía, en este punto, de la siguiente manera:

Que por cuanto no en todas las Inquisiciones hay letrados de confianza con quienes consultar los procesos para sentencia, los inquisidores hagan copiarlos cuando estén conclusos, y remitan copia auténtica por medio del fiscal al inquisidor general, para que los mande ver por letrados del Consejo de inquisición ó por otros de su confianza, los cuales consulten. Despues de esta constitucion se introdujo el estilo de tener letrados titulares, á quienes se nombraba por consultores del Santo Oficio: se les llamaba siempre que había procesos en estado de sentencia; pero como su voto era consultivo, y los inquisidores prevalecian disintiendo, vino el proyecto á ser casi del todo inútil. Se remedió en parte mandándose por cartas acordadas... ${ }^{39}$

Efectivamente, fue otro tipo documental diferente emanado del Consejo, la carta acordada, el instrumento utilizado para incrementar de esta manera la centralización de la actividad de los tribunales dispersos por toda la geografía española. Así, por carta acordada de 1568 se estableció que toda condena a relajación al brazo secular, aún en conformidad, debía ser revisada por el Consejo. Otra carta acordada de 1625 ordenaba que también las condenas a azotes y galeras, impuestas a veces a los reconciliados, debían ser igualmente fiscalizadas por el Consejo. En 1633, de nuevo por carta acordada, se estableció que la sentencia a tormento también tenía que ser revisada por la Suprema; y, por último, ya en 1647, se acordó que todas las sentencias definitivas, incluso las dictadas en conformidad, serían sometidas a la revisión por el Consejo ${ }^{40}$. Como señala Lea, “...con la gradual centralización en la Suprema se exigió que todas las sentencias, fuesen de tortura o de juicio, obtuviesen su confirmación. Debido a esto la consulta de fe fue declinando en importancia, y los tribunales comenzaron a ignorar la formalidad de invocarla e incluso de nombrar a los consultores" 41 .

Se ha señalado anteriormente que el origen de las comunicaciones se encontraba en esta práctica de control por la Suprema de la última fase del proceso instruido

37 H. C. LEA, Historia de la Inquisición..., vol. II, p. 574.

38 V. GONZÁLEZ DE CALDAS, ¿Judios o cristianos?..., p. 453.

39 J. A. LLORENTE, Historia crítica de la Inquisición de España, t. II, Barcelona, 1835, p. 9.

40 V. GONZÁLEZ DE CALDAS, ¿Judios o cristianos?..., p 453.

41 H. C. LEA, Historia de la Inquisición..., vol. II, p. 576. 
ante los tribunales de distrito. Efectivamente, los distintos tribunales de distrito, en este caso el Tribunal de Corte de Madrid, debían remitir todo el proceso, lo que se denominaba la sumaria, a la sede de la Suprema, junto con una carta adjunta, la llamada "comunicación".

Todas las comunicaciones examinadas en este trabajo se encuentran en muy diversos legajos de la Sección de Inquisición del Archivo Histórico Nacional ${ }^{42}$. Todos los legajos aquí citados contienen en su interior unas carpetillas, la mayoría de las cuales llevan el título de "Corte. Comunicaciones al Consejo", y otras, una minoría, el de "Corte. Memoriales al Consejo" o "Corte. Cartas al Consejo". ¿Cuál es la diferencia entre las denominadas comunicaciones, en las que se va a centrar este estudio, y las llamadas cartas o memoriales? En este segundo caso, como se desprende de su lectura, se observa que las cartas y memoriales se refieren a cuestiones de funcionamiento diario del Tribunal de Corte que bien remite éste a la Suprema para su estudio, dictamen y, en su caso, aprobación, o bien porque la $\mathrm{Su}$ prema ha requerido el envío de esa documentación: la solicitud de un puesto de portero u oficial de este Tribunal, la remisión de sus cuentas, petición de mercedes, informaciones de limpieza o genealogías, nombramientos, secuestro de bienes, sueldos, etc.

Sin embargo, cuando en la carpetilla figura el título de "Comunicaciones al Consejo", estamos ante la carta adjunta a toda la causa, actas o sumaria que se enviaba desde el Tribunal de Corte de Madrid a la Suprema ya en la fase final del proceso. La finalidad de este envío era muy clara, como ya se ha señalado: el control y revisión por la Suprema de la sentencia dictada por el Tribunal de Corte.

¿Cuál era el contenido esencial de estas comunicaciones? Por regla general, pues vamos a ver que hay muchas excepciones, eran solo cuatro o cinco los datos mencionados en la comunicación, lo que nos muestra ya una característica esencial de estas comunicaciones: su brevedad. Estos datos eran los siguientes: el número de hojas de que se componía la sumaria enviada junto a la comunicación, el nombre del procesado, el delito del que se le acusaba (blasfemia, con sus correspondientes "variantes" como se verá más adelante), el lugar de nacimiento y residencia del procesado si se conocían, y, por último, el hecho de que la causa estaba ya votada. Un primer ejemplo de comunicación, en este caso de principios del siglo XVIII, aparece en la página siguiente.

Como ya se ha señalado, la principal característica que adornaba a estas comunicaciones, y que se observa tras una primera vista o lectura, era su brevedad, pues aproximadamente diez líneas bastaban para dar a conocer al Consejo, en un primer momento, los antes citados datos esenciales del proceso.

Puede apreciarse en el documento, cuya transcripción literal queda recogida en nota a pie de página ${ }^{43}$, el uso frecuente, normalizado en todo caso en aquella época, de las abreviaturas. ¿Por qué estas abreviaturas? Fundamentalmente era una cues-

42 Para la realización de este trabajo ha sido de enorme interés la consulta del artículo de J. BLÁZQUEZ MIGUEL, "Catálogo de procesos inquisitoriales del Tribunal de Corte", Revista de la Inquisición, $\mathrm{n}^{\circ} 3$ (1994), pp. 205-257, donde se contiene un catálogo con la relación de las causas abiertas por diferentes delitos por el Tribunal de Corte de Madrid, entre ellos el de blasfemia.

43 "En el Cons $^{\circ}$ a 9 de Hen ${ }^{\circ}$ 1706. Al Ror(seguida de la rúbrica). M.P.S. Remito a VA en 21 ojas la sumaria [...] en este despacho por propos ${ }^{\text {nes }}$ blasfemas y hereticales contra Juan Luis de Aranaz de oficio sastre residente en esta Corte votada en la conformidad que VA mandara ver, y a mi lo q devo executar. G [...] a VA $m^{a} y H_{e n}{ }^{\circ}$ 9 de 1706. Don Gregorio Ramos Escajadillo (seguido de la rúbrica)" (AHN, Inquisición, leg. 2506, núm. 6). 
tión de economía de tiempo íntimamente ligada con la enorme burocracia a que daba lugar la incesante actividad de los numerosos tribunales de distrito, en este caso el de Corte de Madrid, que conformaban la estructura territorial del Santo Oficio en la España Moderna. Debe pensarse en los oficiales o secretarios del Consejo de la Suprema, que recibían todos los días decenas de comunicaciones de estos tribunales, con sus respectivas sumarias, que tenían que recepcionar, dejar constancia de haberlas recibido y elevarlas al relator, como ahora se verá. Por ello, era norma general el uso de numerosas abreviaturas para economizar su tiempo, utilizando siempre dos o tres reglas esenciales: cualquier letra podía ser quitada menos la primera; casi siempre se utilizaba, aunque de manera sobrepuesta, la última letra, para así no perder el sentido de esa palabra; y, en consecuencia, se abreviaba quitando algunas letras intermedias. Estas tres reglas se cumplen escrupulosamente en la comunicación aquí incluida, cuyo análisis continuamos.

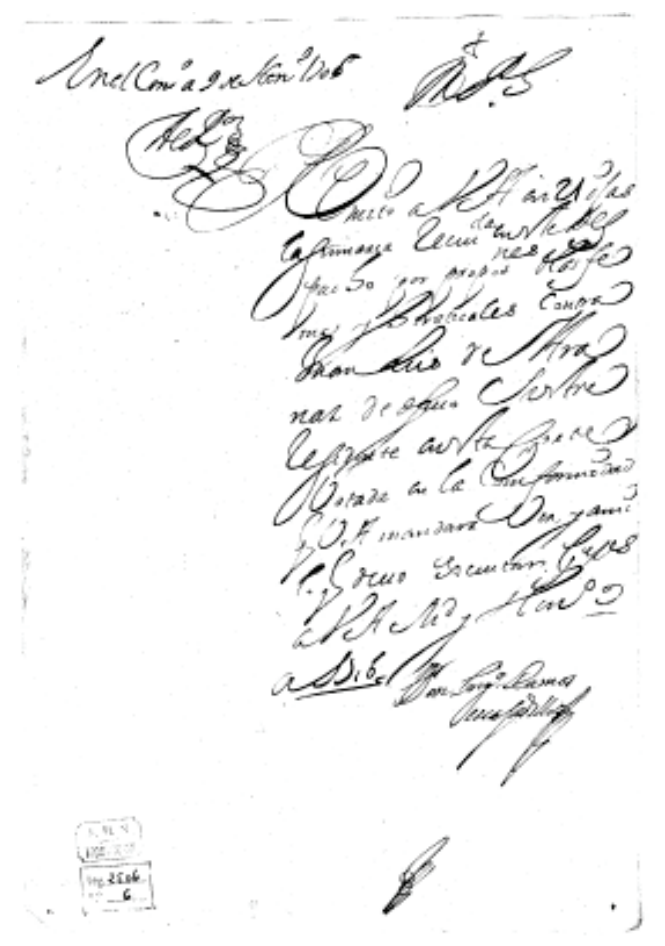

Así, el secretario del Consejo que recibía del Tribunal de Corte de Madrid la sumaria junto con la comunicación dejaba constancia de su recepción arriba a la izquierda de la propia comunicación, indicando la fecha en que se había recibido: "En el Cons ${ }^{\circ}$ a 9 de $\mathrm{Hen}^{\circ} 1706$ ". Por regla general coincidían la fecha de la comunicación del Tribunal de Corte al Consejo, que figura al final del cuerpo de la comunicación, y la de recepción en el Consejo, pues ambos "tribunales" residían en Madrid, de tal manera que enviada la comunicación un día ese mismo día se recibía en el Consejo. Sin embargo, a veces no era así, como en el caso, por ejemplo, de la comunicación enviada al Consejo junto con toda la causa abierta por "blasfemo $e$ Ynjurioso a las stas Ymagenes" contra Miguel García alias el Memo: 
En el Con $^{\circ}$ a 11 de Octe de 1753. S.I. pres ${ }^{\text {te }}$. Al $\mathrm{R}^{\text {or }}$ (sigue la rúbrica). M.P.S. Con esta y en 136 fojas utiles remitimos â VA, votada definitivamente, la causa seguida en este Santo Of $^{\circ}$, contra Miguel Garcia (alias el memo) trahido á estas carceles de [...] de Corte, por blasfemo e Ynjurioso a las stas Ymagenes en cuia vista VA se servira determinar lo que fuese de desuperor agrado, que executtaremos con la mas resignda obed ${ }^{\mathrm{a}}$. Nro. Sr. Ge á VA Ynqu. de Corte y Octe 10 de 1753.

D. P Balth. de Loaisa y Chaves (sigue la rúbrica) ${ }^{44}$.

En este caso, la diferencia entre ambas fechas es mínima, de un solo día, lo que indica que bien se firmó la comunicación en el Tribunal de Corte un día, el 10 de octubre, y se envió al siguiente, o bien habiéndose firmado y enviado la comunicación el mismo día, la acumulación de trabajo en el Consejo impidió a su secretario dejar constancia de su recepción y remitírsela al relator hasta el día siguiente. En alguna ocasión, sin embargo, la diferencia entre ambas fechas llega a los cuatro días, lo que denotaba un cierto atasco en la tramitación de las causas a la hora de su recepción en el Consejo, por enfermedad de los oficiales o secretarios, por alguna festividad o por una puntual congestión de trabajo.

Volviendo a la comunicación de 1706 que se está examinando y cuya imagen se ha insertado anteriormente, vemos que justo debajo de la fecha el secretario del Consejo ha escrito lo siguiente: "Al $R^{\text {or", }}$, lo que indicaba que se remitía toda la sumaria, junto con la comunicación del Tribunal de Corte, al relator.

La función del relator era, precisamente, como su nombre indica, hacer un resumen o relación de la causa una vez recibida. Era ésta una tarea que requería de enorme volumen de tiempo y energía, hasta el punto de que prácticamente eran los únicos oficiales al servicio del Santo Oficio a los que se permitía extraer de "sede inquisitorial" la documentación para su trabajo en casa: “...los relatores, a quienes les era permitido llevar los papeles en bolsa de terciopelo negro para que no se pudiera adivinar su contenido. Si las llevaban los criados, las bolsas debían tener cerradura para evitar tentaciones" ${ }^{45}$. Era incluso, según testimonio recogido por Rodríguez Besné, un cargo considerado de mayor trabajo y dedicación que los propios secretarios:

Aunque se neçesita mucho de las personas de los secretarios y es grande su asistencia y trabajo, no es dudable que se neçesita mas y es mucho mayor el de los Relatores porque fuera de las horas del Consejo están continuamente de dia y de noche desvelándose y trabajando en sus cosas y a muchos les a costado la vida y a otros enfermedades y achaques, y en faltando uno estancan los negocios y se suspenden las causas $^{46}$.

44 Comunicación del Tribunal de Corte de Madrid al Consejo de la Inquisición, de 10 de octubre de 1753, en la causa seguida contra Miguel García alias el Memo (AHN, Inquisición, leg. 2521, caja 2, núm. 4).

45 S. CABEZAS FONTANILLA, "El archivo del Consejo de la Inquisición ultrajado por Gaspar Isidro de Argüello, secretario y compilador de las Instrucciones del Santo Oficio", Documenta\&Instrumenta, n 2 (2004), pp. 7-22, 12.

46 J. R. RODRÍGUEZ BESNÉ, El Consejo de la Suprema Inquisición, Madrid, 2000, pp. 61-62, tomado por el autor de AHN, Inquisición, libro 1331, fol. 66. 
En los tribunales de distrito no existía la figura del relator, por lo que los inquisidores se veían obligados a consultar detenidamente la causa para emitir su sentencia. Sin embargo, en la Suprema, esta función de lectura y posterior redacción de la relación o resumen de los papeles de la causa correspondía a los relatores ${ }^{47}$. De ahí esa expresión "Al Relator", que figura en todas las comunicaciones del Tribunal de Corte a la Suprema, y por medio de la cual el secretario daba cuenta de que la causa o sumaria pasaba a manos de este oficial para efectuar la citada relación.

A continuación, en el documento, podemos observar el cuerpo de la comunicación precedido de la expresión "M.P.S.", a veces figura como "M.P.Sr", cuyo significado es "Muy Poderoso Señor". Dado que en todas las comunicaciones esta expresión tiene el mismo tipo, trazo y grosor de letra que el cuerpo del documento, queda acreditado que quien la escribe es la misma persona, un escribano del tribunal de Corte, que escribe el cuerpo de la comunicación, dirigiéndose, claro está, al Inquisidor General, quien preside la Suprema, órgano al que va dirigido la comunicación del Tribunal de Corte de Madrid.

Ya en el cuerpo central o parte dispositiva de la comunicación, se encuentran los cuatro o cinco datos esenciales antes mencionados y que toda comunicación contenía, siempre que se conocieran todos ellos. En primer lugar, el número de hojas de que constaba la sumaria remitida: "Remito a VA en 21 ojas la sumaria [...] en este despacho...". En esa cifra, veintiuno, siempre se incluía la propia comunicación. Esta cifra podía llegar a ser muy abultada, pues hasta centenares de hojas podía llegar a sumar una causa seguida en el Tribunal de Corte. Fue el caso, por ejemplo, de la sumaria resultado del proceso abierto contra Cristóbal de Monterrubio por "solicitante, proposiziones hereticas, y blasfemias":

En el Consejo a 10 de Marzo de 1703. Al R ${ }^{\text {or }}$. M.P.Sr. Remito a V.A. en 2 piezas la una en 393 foxs. y la otra en 297 el proceso causado en este Despacho contra Fr. Christoval de Monterrubio Religioso sacerdote Dominico preso en estas Carzs. por solicitante, proposiziones hereticas, y blasfemias, votado en definitiva, en la conformidad que V.A. mandara ver y a mi lo que deva ejecutar. G. Dios a V.A. [...] y Marzo 10 de 1703. Don Gregorio Ramos Escajadillo.

Nada menos que 690 hojas constituían esta causa, por lo que como señala la comunicación, se remitieron en dos piezas separadas, en dos legajos, por la imposibilidad física de reunirlas en una sola.

Otro de los datos principales que se incluían en las comunicaciones era, lógicamente, la indicación del delito cometido: la blasfemia. En la comunicación datada en 1706 que se está analizando, el delito por el que había sido juzgado el procesado, Juan Luis de Aranaz, era el de "propo ${ }^{\text {nes }}$ blasfemas, y hereticales", es decir, proposiciones blasfemas hereticales. En este punto, conviene detenerse para estudiar con detenimiento la calificación que merecieron conductas que bien pudieran todas calificarle como simples blasfemias, pero que requerían en primer lugar de su calificación como heréticas para ser conocidas por el Santo Oficio: blasfemias he-

47 V. GONZÁLEZ DE CALDAS, ¿Judios o cristianos?..., p. 328. 
reticales, y que otras veces eran calificadas como simples proposiciones, o incluso de alguna otra manera como se verá a continuación.

A partir del siglo XVIII, centuria en la que se encuadra esta causa contra Juan Luis de Aranaz que se está analizando, fue descendiendo el número de procesos por blasfemia al mismo tiempo que se incrementó el de los seguidos por las denominadas proposiciones. Ya se ha indicado al comienzo de este trabajo que el concepto de proposición, aunque difuso, podía acercarse al de aseveración o afirmación peligrosa contra la fe. Pero dentro de este concepto general podía hacerse una clasificación que, como siempre, variaba según los autores. Al respecto, Santiago Medina señala que según “...su contenido, las proposiciones recibían diferentes nombres (herética, escandalosa, blasfema...), adscribiéndose así a una tipología previamente establecida. Sin embargo, las categorías no eran excluyentes y se podía pertenecer a varias de ellas a la vez" ${ }^{48}$. Y recoge a continuación la clasificación que de las proposiciones realizó Caesar Carena en su Tractatus de Officio Sanctissimae Inquisitionis, dividiéndolas entre otros tipos, en heréticas, erróneas, temerarias, etc ${ }^{49}$.

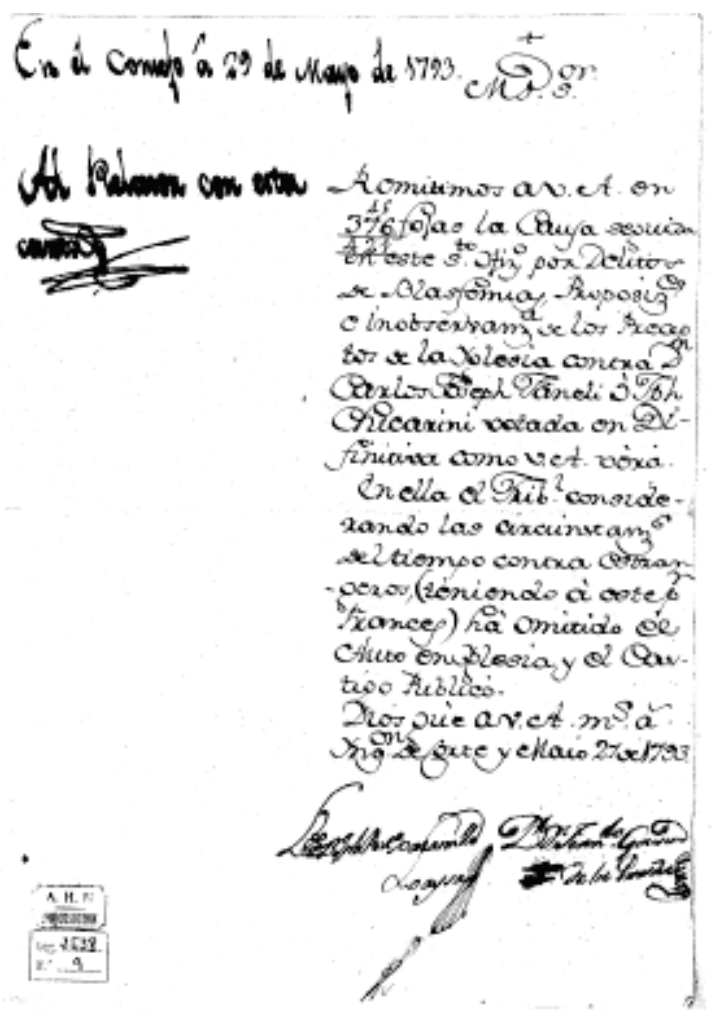

Bajo el tipo penal de "proposiciones heréticas", o "hereticales", citado tantas veces en estas comunicaciones entre el Tribunal de Corte de Madrid y el Consejo,

48 B. SANTIAGO MEDINA, "De buenas o malas calidades...”, p. 309.

49 Ibídem, pp. 310-311. 
los calificadores encontraron la posibilidad de encuadre de expresiones que dificilmente podían calificarse como blasfemia, o sí. El problema residía en que el deslinde entre una y otra calificación no estaba nada claro ni para los propios calificadores, que utilizan cuatro o cinco tipos penales diferentes para calificar expresiones muy similares. Por ejemplo, en una comunicación del Tribunal de Corte al Consejo, de 27 de mayo de 1793, en causa seguida contra dos extranjeros, Carlos Joseph Faneli y Joseph Chicarini, se califican los hechos como "delitos de Blasfemias, y Proposiziones" $"$ :

No se señalan aquí las expresiones merecedoras de tal calificación, pues nunca se incluían para evitar extender en demasía las comunicaciones. Por ello hay que acudir a los resúmenes de las alegaciones fiscales que acompañaban, dentro del conjunto de hojas de la sumaria, a la comunicación. Allí si se pueden leer, textuales, las expresiones calificadas de una u otra manera. Por ejemplo, en el citado resumen de las alegaciones que realizó el fiscal de la causa abierta contra Manuel Alarcón, por blasfemo, en 1747, se puede leer:

El Fiscal de Corte contra Manuel de Alarcon, natural de Benavente y residente en esta Corte, y de oficio [...] Por blasfemo. En 18 de Julio de 1747 [...] parecio de su voluntad en esta Corte Maria Pujadas de estado casada de 25 años que para descargo de su conciencia, delato al reo, hace como mes y medio, que estando de [...] en su quarto principal [...] Corredera de San Pablo oio a este reo (que vive en el quarto ultimo de esta casa) decia estas blasfemias.- Me cago en la Virgen del Carmen con su hijo que tiene en los brazos, y en Dios- y que esto lo oio la denunciante, una vez, no mas, con motivo de estar el reo viviendo con dicha [...] que tenia en su compañía y esto mismo lo oio Maria $[\ldots]$ mujer de $[\ldots]$ en dicha casa $^{51}$.

Ejemplo éste típico de blasfemia, encontramos otro similar en la causa seguida en 1749 contra Ignacio César "por mal nombre el Zalamero". En el correspondiente resumen de alegaciones del fiscal, Juan Lacy, señala éste que compareció María Pérez quien declaró que el tal Ignacio César profirió varias veces, entre otras, las siguientes expresiones: "mala ostia sea la alma de Dios, de Maria S. por vida de las tripas de Dios, y de la Virgen", "me cago en Dios y en la Virgen", "por vida de la hostia de Dios y de Jesus Nazareno", etc ${ }^{52}$.

Ahora bien, siendo esto lo más frecuente, no fueron pocos los procesos abiertos, por expresiones similares, calificadas como "blasfemias hereticales" o "ereticales", pues se encuentran ambas expresiones indistintamente:

En el Consejo a 10 de Junio de 1734. M.P.S. Con esta remitimos a V.A. en 78 fojas utiles, el proceso [...] en este Sto. Ofizio contra Ant. Marcos de ofizio zapatero y vecino de esta Corte, por delitos de Blasfemias ereticales, votado en difini-

50 Comunicación del Tribunal de Corte al Consejo de la Inquisición, de 27 de mayo de 1793, en la causa abierta contra Carlos Joseph Faneli y Joseph Chicarini (AHN, Inquisición, leg. 2538, caja 2, núm. 9).

51 Resumen de alegaciones fiscales en la causa seguida contra Manuel de Alarcón, en 1747 (AHN, Inquisición, leg. 3736, exp. 45).

52 Resumen de alegaciones del fiscal, don Juan Lacy, en la causa abierta contra Ignacio César "por mal nombre el Zalamero", en 1749 (AHN, Inquisición, leg. 3736, exp. 38). 
tiva en la conformidad que V.A. se servirá ver y mandar lo que fuere servido. Nro. Sr. Guarde a V.A. Ynqq ${ }^{\text {on. }}$ de Corte 10 de Junio de 1734. Ldo. Pablo de [...] Castillo $^{53}$.

Muy frecuente, igualmente, era la calificación de este tipo de expresiones como "dichos y hechos hereticales":

En el Consejo a 8 de Julio de 1739. Al Rel ${ }^{\text {or }}$. M.P.S. Con esta y en 39 fojas utiles remito a V.A. la Sumaria ynformazion recivida en este Sto. Ofizio contra $\mathrm{F}^{\mathrm{co}}$. Damien alias framiel de Nacion Ginebrino soldado valon preso en la Carzel real de Corte sobre echos y dichos hereticales de vana observancia, votada en la conformidad que V.A. se servira mandar ver y a mi lo que deba executar. Ntro. Sr. Gu. a V.A. Inqq. de Corte y Julio 8 de 1739. Don Pablo de [...] Castillo ${ }^{54}$.

Tampoco era infrecuente que la calificación cambiara varias veces con el transcurso del proceso, como le ocurrió al presbítero Mathías de Moncayo, como puede fácilmente comprobarse en las comunicaciones, muy numerosas en esta causa, remitidas por el Tribunal de Corte al Consejo de la Inquisición. Así, en sendas comunicaciones de 7 de julio y 1 de agosto de 1702, respectivamente, cuando todavía el procesado estaba en la cárcel secreta de la Inquisición, se señalaba que el proceso se ha abierto por "blasfemo heretical". Curiosamente, solo unos meses más tarde, en una Relacion de las causas que ay pendientes en esta Inq. de Corte datada el 6 de noviembre del mismo año, se incluía la iniciada contra Mathías de Moncayo "por proposiciones escandalosas". En una tercera comunicación, de 16 de marzo de 1703, la calificación del delito volvía a ser la primera y original: "blasfemo heretical'. Pero en una cuarta y última, el 31 de marzo de 1703, en la que se criticaba, muy veladamente, la decisión del Consejo de dejar en libertad al mismo Mathias de Moncayo, se señalaba expresamente que había estado preso en las cárceles del Santo Oficio por "proposiciones y blasfemias hereticales" $"$. Como se verá más adelante, no fue éste el único caso en el que la calificación de los hechos varió a lo largo de los meses de instrucción del proceso.

De nuevo de regreso a la comunicación del Tribunal de Corte de Madrid a la Suprema del año 1706, en la causa contra Juan Luis de Aranaz, se aprecia que además del nombre del procesado, que se recogía completo cuando se conocía, se acompañaba en algunos casos su mote, si es que lo tenía, y se conocía, para una mejor identificación del encausado: "Alias el Abate Roscuet", "Joseph [...] alias de la freixía"57, "Joseph Perez Soriano, alias el Marques" " Y a continuación,

53 Comunicación del Tribunal de Corte de Madrid al Consejo de la Inquisición, de 10 de junio de 1734 (AHN, Inquisición, leg. 2514, núm. 6).

54 Comunicación del Tribunal de Corte de Madrid al Consejo de la Inquisición, de 8 de julio de 1739, en la causa seguida contra Francisco Damien (AHN, Inquisición, leg. 2514, núm. 11).

55 Comunicaciones del Tribunal de Corte de Madrid al Consejo de la Inquisición, datadas, respectivamente, los siguientes días: 7 de julio de 1702, 1 de agosto de 1702, 6 de noviembre de 1702, 16 de marzo de 1703 y 31 de marzo de 1703 (AHN, Inquisición, leg. 2506, núms. 2 y 3).

56 Comunicación del Tribunal de Corte al Consejo de Inquisición, de 12 de marzo de 1744, en la causa contra Francisco Audrion de Roscovet (AHN, Inquisición, leg. 2515, núm. 6).

57 Relazion de las Causas de fee, pendientes, en este Santo Officio de la Inqqn. de Corte (AHN, Inquisición, leg. 2511, exp. 2). 
también solo si se conocía, lo que no ocurría siempre, su oficio. Personas de toda condición y oficio fueron denunciadas y procesadas por este delito de blasfemia; así, por ejemplo, en las comunicaciones del Tribunal de Corte a la Suprema, correspondientes al siglo XVIII, se puede encontrar un clérigo, un secretario del Secreto del propio Santo Oficio, un ama de casa, un soldado, un zapatero, un sepulturero, un sacerdote dominico, un aspirante a oficial de la Inquisición, otro soldado en este caso de la Real Guardia Valona de Infantería, etc. ${ }^{59}$. Incluso Cenón de Somodevilla y Bengoechea, secretario de Estado y del Despacho de Guerra, Hacienda y Marina e Indias, todopoderoso ministro del rey Felipe $\mathrm{V}^{60}$, fue denunciado por hallarse en su residencia una "pintura provocativa, y escandalosa" susceptible de calificarse como blasfema, como así consta en una comunicación del Tribunal de Corte de Madrid al Consejo de la Inquisición de 7 de julio de $1745^{61}$. Como queda evidenciado, y solía decirse, nadie, salvo el rey, quedaba a salvo de la larga mano de la Inquisición, aunque fuera por un delito "menor" como la blasfemia.

Para concluir el cuerpo del documento, en estas comunicaciones encontramos dos fórmulas rituales, que se repiten inexorablemente en todas ellas. La primera, la indicación por parte del Tribunal de Corte a la Suprema de que la causa ya está votada en el seno de este tribunal; en la comunicación de 1706 que analizamos: "votada en la conformidad", lo que permitía conocer que se había dictado el fallo por unanimidad; pero que podía variar muy ligeramente si esa unanimidad no se había producido con un simple "votada", o "votada a prisión en carzeles secretas" cuando la comunicación a la Suprema se producía al inicio del proceso y se informaba a ésta que el sospechoso estaba recluido en las cárceles inquisitoriales, o a veces "votado en definitiva", es decir, mediante sentencia presta ya a ejecutarse.

La segunda de las fórmulas rituales, obligatorias, que figuraban al final de toda comunicación, era aquella en virtud de la cual el Tribunal de Corte expresaba su futura conformidad con lo dispuesto por el Consejo de la Inquisición, tras la revisión que éste realizaba de la causa remitida por el Tribunal de Corte: "y a mi lo q devo executar". Fórmula que también adoptó otras variantes: "VA nos ordene lo que fuere de su agrado", "que VA se servirá ver, y a nosotros en su conseqa. lo que sea del $\mathrm{mr}$. agrado de VA", "que VA para el mar. acierto fuere servido ordenarnos", etc. De esta manera, el Tribunal de Corte ya anunciaba su conformidad, como

58 Comunicación del Tribunal de Corte al Consejo de la Inquisición, de 22 de diciembre de 1727, en la causa seguida contra Joseph Pérez Soriano (AHN, Inquisición, leg. 2513, núm. 4).

59 Comunicaciones del Tribunal de Corte de Madrid a la Suprema, en los procesos contra Francisco Audrion de Roscovet (AHN, Inquisición, leg. 2515, núm. 6); Francisco Martínez Cabezón (AHN, Inquisición, leg. 2515, núm. 10); Francisca Ximenez (AHN, Inquisición, leg. 2515, núm. 11); Francisco Heredia (AHN, Inquisición, leg. 2514, núm. 3); Antonio Marcos (AHN, Inquisición, leg. 2514, núm. 6); Fernando Navarro (AHN, Inquisición, leg. 2514, núm. 9); Cristóbal de Monterrubio (AHN, Inquisición, leg. 2506, núm. 3); Gonzalo López de Lamas (AHN, Inquisición, leg. 2506, núm. 4); y Francisco Román (AHN, Inquisición, leg. 2519, núm. 4).

60 J. A. ESCUDERO, "La reconstrucción de la Administración central en el siglo XVIII", en Historia de España de Menéndez Pidal, t. XXIX, Madrid, 1985, pp. 78-175, 129.

${ }_{61}$ La comunicación es la siguiente: "En el Consejo a 7 de Julio de 1745. M.P.S. Con esta remitimos a V.A. la delacion echa en este Sto. Oficio, por D. Franco Antonio de Basaguren, Presvitero, de una pintura provocativa, y escandalosa que se halla puesta en uno de los salones principales de la Casa, que havita el marques de la Ensenada, para que V.A. se sirva mandarnos, lo que debamos executar. Nro. Sr. guarde a V.A. Inqqon. de Corte, y Julio 7 de 1745. D. Joseph Zorilla de Martin" (AHN, Inquisición, leg. 2515, núm. 7). No se ha podido encontrar documentación alguna que acredite que se iniciara posteriormente por el Consejo causa contra el marqués de la Ensenada, por lo que es de suponer que el Inquisidor General decidió archivar la denuncia ante la escasa trascendencia de los hechos. 
no podía ser de otra forma, con la decisión a adoptar por el Consejo a la vista de la relación o resumen del relator.

Por último, la protocolaria salutación final o cláusula de despedida: "Guarde Dios a VA muchos años", que siempre se incluía con anterioridad a la fecha, y con la que "...se pone fin al escrito y el otorgante expresa al destinatario sentimientos de respeto, estima o protección”, 62 y la data: “...y Henero 9 de 1706”, es decir, el mes, día y año expresados los dos últimos mediante numerales. Más tarde se verá como en comunicaciones de finales del mismo siglo XVIII esta fórmula varió hasta la habitual hoy en día, es decir, primero el día, después el mes y por último el año.

Para finalizar esta comunicación del Tribunal de Corte al Consejo de la Inquisición en la causa contra Juan Luis Aranaz, nos encontramos con la denominada "firma entera", tan habitual, por otra parte, en los documentos expedidos por la Administración española en ese siglo XVIII. Dicha firma entera estaba compuesta por el nombre y apellidos de quien suscribía la comunicación, y con su rúbrica, muy sencilla. En este caso, quien suscribe era "Don Gregorio Ramos Escajadillo", por aquellas fechas inquisidor ordinario para asuntos de Hacienda del Tribunal de Corte de Madrid en virtud de nombramiento recibido el 21 de octubre de 1702 del inquisidor general Mendoza y Sandoval ${ }^{63}$.

Una última cuestión respecto a la diplomática de estas comunicaciones: en cuanto al tipo de letra utilizado, en el siglo XVIII se produce un abandono generalizado de la denominada escritura "itálica", propia de siglos anteriores, por otra definida como "entreredonda" o "pseudorredonda", mucho más legible que la anterior, y que va adquiriendo carta de naturaleza conforme transcurre el siglo XVIII. Como indica Gómez Gómez, "en una época de racionalización y pragmatismo, de ilustración y eficacia, la escritura, medio, pero no fin, de la puesta por escrito de los documentos, se desenvuelve más ligada y cursiva, más redondeada, menos estilizada y, como consecuencia, más ágil en su ejecución" ${ }^{\circ 4}$. Características éstas de la escritura que pueden apreciarse a simple vista en las imágenes en este trabajo insertas.

Hasta aquí el análisis diplomático de una comunicación del Tribunal de Corte al Consejo de la Inquisición a principios del siglo XVIII. Como ya se ha indicado, estas comunicaciones experimentaron a lo largo de esta centuria algunas modificaciones, como así ocurrió con el resto de la documentación expedida por la "maquinaria administrativa" de la España Moderna. Cambios no tanto en su forma de expedición, como en sus características formales. Así, cabe señalar que de manera similar a como se hacía en las Secretarías de Estado y del Despachoo ${ }^{65}$, las comunicaciones del Tribunal de Corte, ya a partir de mediados del siglo XVIII, eran enviadas al Consejo de la Inquisición junto con otra hoja, ambas unidas a modo de cuadernillo. En el anverso de la primera, cuyo reverso estaba en blanco, se anunciaba, de manera aún mucho más breve, el contenido de la sumaria que se enviaba:

62 M. GÓMEZ GÓMEZ, Forma y expedición del documento en la Secretaría de Estado y del Despacho de Indias, Sevilla, 1993, p. 231.

63 El 18 de abril de 1708 Ramos Escajadillo y Posada fue ascendido al Consejo (M ${ }^{\text {a }}$ del PILAR DOMÍNGUEZ SALGADO, "Inquisidores y fiscales...", p. 218)

64 M. GÓMEZ GÓMEZ, Forma y expedición del documento..., p. 255.

65 Sobre esta cuestión resulta indispensable la consulta de la obra ya citada de M. GÓMEZ GÓMEZ, Forma y expedición del documento.... 
"Corte 20 de Octubre de 1755. El Tribl. con la causa contra D". Pedro Quintanar Espiga por blasfemo" ${ }^{66}$. Otras veces, en esa primera hoja se daba cuenta del contenido de la comunicación, indicando la realización de un trámite procesal concreto: "Corte 16 de Feb ${ }^{o}$. de 1753. El Tribl avisa haver dado cumplim ${ }^{\text {to }}$ al auto del Cons ${ }^{\circ}$ sobre la causa de $D^{n}$ Ant ${ }^{\circ}$ Man ${ }^{l}$ de Yllescas".

Otro ejemplo de lo señalado:

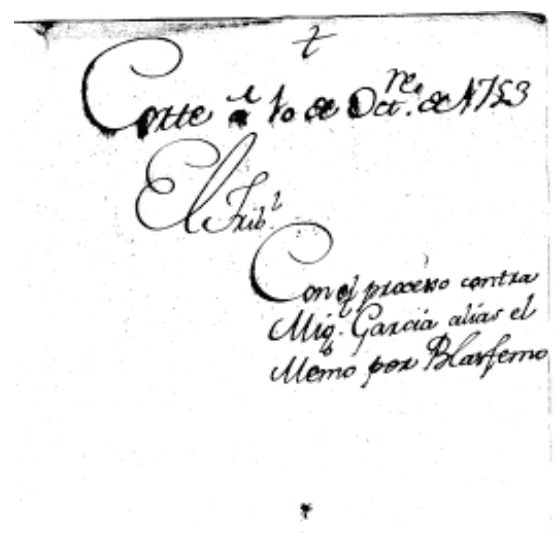

En el anverso de la segunda hoja encontramos la comunicación propiamente dicha, mientras que su reverso estaba en blanco salvo que la comunicación fuera más extensa, lo que solía ocurrir cuando se producía a mitad del proceso y el Tribunal de Corte comunicaba a la Suprema las actuaciones practicadas hasta el momento, la situación del procesado, etc.

Sin embargo, no fue esta práctica, la de insertar la comunicación en un cuadernillo, una costumbre generalizada en el Tribunal de Corte y que se impusiera de manera definitiva a partir de una fecha determinada, pues se ha observado que todavía a finales de siglo un gran número de comunicaciones seguían conservando su formato habitual, es decir, estaban incluidas en el anverso de la primera y única hoja.

Otra de las peculiaridades formales de estas comunicaciones del Tribunal de Corte, a finales del siglo XVIII, fue su simplificación o aclaración con respecto a las redactadas a primeros de siglo. Brevedad y concisión son dos de los principios a observar por los oficiales y/o escribanos, en esta centuria, a la hora de elaborar todo tipo de documentación emanada del Estado ${ }^{67}$. Ahora disminuyen considerablemente las abreviaturas, de tal forma que expresiones como " $A l R^{o r "}$ ", $T r i b$ " o "Ynq $q^{\text {on" }}$ se convierten en "Al Relator", "Tribunal" e "Ynquisicion", respectivamente; la fecha viene indicada en el formato día-mes-año, como se hace en la actualidad: "19 de abril de 1796", y no mes-dia-año como se realizaba a principios del siglo XVIII; $\mathrm{y}$, en general, se observa un documento más limpio, ordenado y de más fácil lectura que los de principios de siglo. A título de ejemplo, se inserta una comunicación de 1796:

\footnotetext{
66 Comunicación del Tribunal de Corte al Consejo de la Inquisición, de 20 de octubre de 1755 (AHN, Inquisición, leg. 2521, caja 2, no 6).

67 M. GÓMEZ GÓMEZ, Forma y expedición del documento..., p. 193.
} 


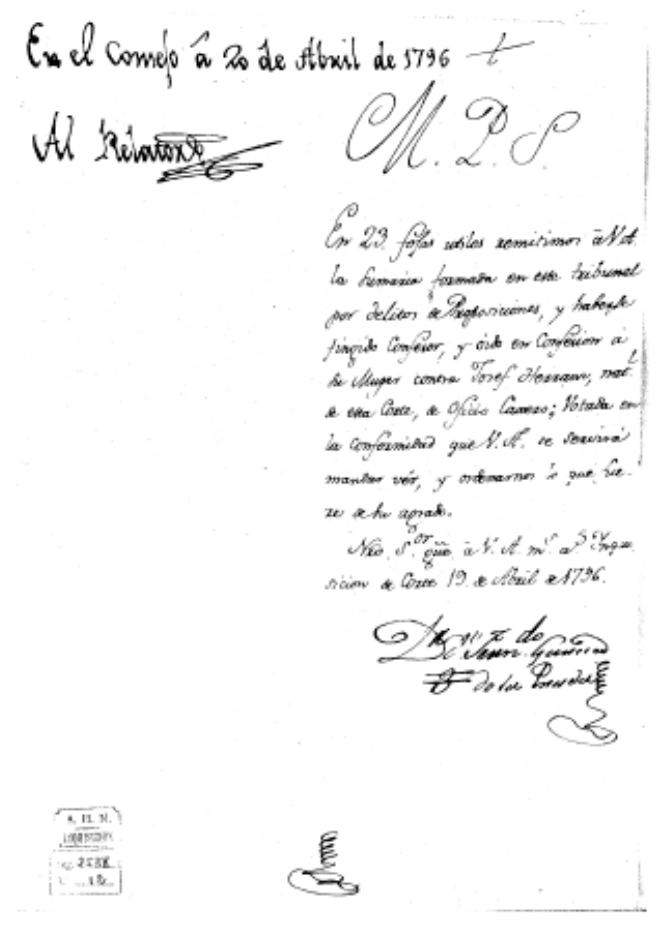

\section{El proceso contra Francisco Román a través de las comunicaciones del Tri- bunal de Corte al Consejo de la Inquisición}

No se quiere concluir este trabajo sin aludir a una cuestión esencial. Como se ha venido exponiendo, la mayoría de las comunicaciones aquí analizadas tenían por objeto dar cuenta al Consejo del envío de todas las actas o sumaria de diversas causas por blasfemia. Sin embargo, las comunicaciones del Tribunal de Corte al Consejo se producían, conforme al control cada vez más acentuado que la Suprema ejercía de la actividad de los tribunales de distrito, desde el inicio del proceso hasta el final del mismo. Por ello, sin necesidad de consultar todas las hojas de la sumaria, por otro lado en muchos casos desaparecidas, se puede seguir el iter del procedimiento de cualquiera de las causas desde sus comienzos hasta la confirmación por el Consejo de la sentencia dictada en estos tribunales de distrito, como el Tribunal de Corte de Madrid.

A continuación se transcriben cuatro comunicaciones de este tribunal al Consejo de la Inquisición con ocasión de la causa abierta en 1751 contra Francisco Román. En ellas, además de poder examinar los diferentes pasos dados por el Tribunal de Corte, puede perfectamente apreciarse cómo la calificación de los hechos de los que se acusaba a este soldado varió con el transcurso del proceso. Se trata, por tanto, de una causa muy interesante, cuya primera comunicación fue la siguiente:

En el Cons. a 28 de Mayo de 1751. Al Relator. M.P.S. Con esta, y en 63 foxas utiles, remitimos a V.A., la sumaria rez ${ }^{\mathrm{da}}$, es este $\mathrm{S}^{\text {to }} \mathrm{Off}^{\mathrm{o}}$, contra Fran ${ }^{\mathrm{co}}$ Roman, 
soldado del Rexim ${ }^{\text {to }}$ de Gua $^{\text {as }}$ Españolas por el delito de haver proferido varias Blasfemias, preso en el calabozo de dho rexim ${ }^{\text {to }}$, por desertor, y [...] encargado en el, de orn de este trib ${ }^{1}$, con aprobacion de V.A., por su Decreto de 28 de Abril prox $^{\text {mo }}$ pasado; Votado a prission, en la conform ${ }^{\mathrm{d}}$, que V.A. se servira mandar ver, y a nosotros, lo que debamos executar, deseosos spre del $\mathrm{m}^{\text {or }}$ acierto, en prueba de nra rendida obed ${ }^{\mathrm{a}}$. Nro. Sr. G ${ }^{\mathrm{e}}$ a V.A.\&Ynq ${ }^{\mathrm{n}}$ de Corte y Mayo 28 de 1751. Fermin Jph. Charola ${ }^{68}$.

Cabe señalar dos datos importantes de la anterior comunicación: por un lado, que Francisco Román estaba preso en el calabozo, a disposición de las autoridades militares, por desertor; y, por otro, que también se le había abierto causa en la Inquisición por "el delito de haver proferido varias Blasfemias". Sin embargo, en la siguiente comunicación, enviada solo una semana después, vemos que Francisco Román ya estaba preso en las cárceles del Santo Oficio y que el delito del que era acusado ya no era el de simples "Blasfemias", sino el de "blasfemias hereticales":

En el Cons. a 5 de Junio de 1751. Su Ill ${ }^{\mathrm{ma}}$ pres $^{\text {te }}$ A su lugar. M.P.S. Estando votada por este tribunal, y confirmada por Decreto de V.A. de 2 del corr ${ }^{\text {te }}$, a prision, la persona de Fran $^{\text {co }}$ Roman, soldado del Rexim ${ }^{\text {to }}$ de Guar ${ }^{\text {as }}$ Españolas, por delitos de blasfemias hereticales, detenido en el calabozo de su Quartel a disposicion del $\mathrm{S}^{\text {to }} \mathrm{Off}^{\mathrm{o}}$, fue remobido de él a estas carzeles anoche 4 del corr ${ }^{\mathrm{te}}$, con el mayor silencio, precediendo el recado de estilo a sus Gefes: De lo que damos q q $^{\text {ta }}$ a V.A.

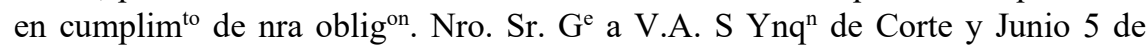
1751. Fermin Jph de Charola ${ }^{69}$.

¿Qué había pasado en el escaso plazo de una semana? Se adivina un intento del Santo Oficio, exitoso por otro lado, de intentar avocar hacía sí el conocimiento de esta causa. Por ello, se cambió la calificación del delito, pues lo que eran unas simples "blasfemias", cuyo conocimiento no correspondía a la Inquisición, por "blasfemias hereticales", cuyo conocimiento ahora sí entraba en el ámbito jurisdiccional material del Tribunal de Corte de Madrid. De ahí su traslado a las cárceles secretas del Santo Oficio, imponiéndose la jurisdicción inquisitorial a la ordinaria y, desde luego, al menos en el tiempo, a la militar, pues su delito por deserción sería juzgado y castigado más tarde.

En los meses de verano de 1751 fue instruida la causa contra Francisco Román en el Tribunal de Corte, practicándose todas las pruebas necesarias. De todo ello resultó una sumaria con un total de doscientas cincuenta y nueve hojas, que se remitió al Consejo de la Inquisición el 11 de septiembre del mismo año señalando que ya había sido votada "en difinitiva". Curiosamente, de nuevo volvió a cambiar la calificación de las expresiones vertidas por el soldado, y por las que estaba siendo juzgado, pues ahora aparecen como "hechos, y dichos hereticales":

68 Comunicación de Tribunal de Corte de Madrid al Consejo de la Inquisición, de 28 de mayo de 1751, en la causa abierta contra Francisco Román (AHN, Inquisición, leg. 2519, carp. 4).

69 Comunicación de Tribunal de Corte de Madrid al Consejo de la Inquisición, de 5 de junio de 1751, en la causa abierta contra Francisco Román (AHN, Inquisición, leg. 2519, carp. 4). 
En el Cons. a 11 de Sep $^{\text {re }}$ de 1751. Su Ill $^{\text {ma }}$ pres $^{\text {te }}$ Al Relator M.P.S. A esta acompaña en 259 fojas utiles la causa, que en este $\mathrm{S}^{\text {to }} \mathrm{Of}^{\mathrm{o}}$ se ha seguido $\mathrm{p}^{\text {or }}$ hechos, $\mathrm{y}$ dos heretic ${ }^{\mathrm{s}}$, contra Fran ${ }^{\mathrm{co}}$ Roman nat ${ }^{\mathrm{l}}$ de la Ciud ${ }^{\mathrm{d}}$ de Tarifa, soldado de los $\mathrm{r}^{\mathrm{s}}$ Guardias españolas de ynfanteria; votada en difinitiva en los terminos q VA se servira mandar ver, y a nosotros lo $\mathrm{q}^{\mathrm{e}}$ fuere de su super ${ }^{\text {or }}$ voluntad, $\mathrm{q}^{\mathrm{e}}$ executaremos como es de nra obliga ${ }^{\text {on }}$. Nro Sr g a VA Ynq ${ }^{\text {on }}$ de Corte y Sep 11 de 1751. Fermin Jph de Charola ${ }^{70}$.

El proceso contra Francisco Román terminaba unos días después, a finales del mismo mes de septiembre de 1751, como se deduce de la última comunicación al respecto de esta causa enviada por el Tribunal de Corte a la Suprema. En ella pueden advertirse igualmente tres datos interesantes; el primero, que el secretario u oficial del Consejo que recibe la comunicación ordena enviar esta comunicación, dado que se ha cumplido la sentencia, "A su legajo", quedando así archivada junto con el resto de la causa anteriormente remitida; el segundo, la levedad de las penas impuestas: abjuración de levi, absolución ad cautelam, reprensión, cárcel por quince días, confesión general e instrucción en la fe católica. Como ya se ha comentado, estas penas "menores" se impusieron muy frecuentemente para castigar un delito también considerado "menor", en numerosos casos, por el Santo Oficio. Y, el tercer y último dato, pero quizás el más importante, la circunstancia de que por cuarta vez se procedió a cambiar la calificación de los hechos, que ahora eran ya "Propp ${ }^{\text {nes", }}$ es decir, proposiciones. Lo que da a entender que el Consejo de la Inquisición, al examinar toda la causa recibida del Tribunal de Corte el 11 de septiembre, decidió no conformarse con su calificación y cambiarla a "proposiciones" con su correspondiente pena: "como V.A. se sirvio mandarnos por su Decreto de 15 del presente". Esta última comunicación, de 25 de septiembre de 1751 , y con la que se concluye la causa contra Francisco Román, dice así:

En el Cons. a 25 de Sep $^{\text {re }}$ de 1751. A su legajo (seguida de la rúbrica) M.P.S. En la mañana del dia 22 del corr ${ }^{\text {te }}$ fue despachado Fran $^{\text {co }}$ Roman, $\mathrm{Nat}^{1}$ de la $\mathrm{Ciu}^{\mathrm{d}}$ de Tarifa, soldado de las Guar ${ }^{s}$ Españolas de Ynfanteria, preso en carzeles secretas de este $\mathrm{S}^{\text {to }}$ Offo con sequestro de sus bienes, por delitos de Propp ${ }^{\text {nes}}$; a quien se le leyó su senz ${ }^{a}$ con meritos, abjuró de Levi, fue absuelto ad cautelam, advertido,

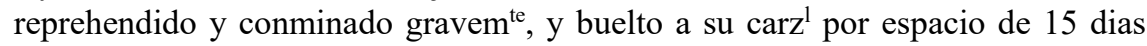
para que en ellos haga una confession general, y se le instruya y fortifique en los Mysterios de Nra $\mathrm{S}^{\text {ta }}$ Fee, como V.A. se sirvio mandarnos por su Decreto de 15 del presente: Para cuyo efecto nombramos al $\mathrm{P}^{\mathrm{e}}$ Carlos Lambert de Clerigos menores, y califi ${ }^{r}$ del $\mathrm{S}^{\text {to }}$ Officio, quien asiste con puntualidad, y zelo y continuará para el expresado fin. Lo que paratipp ${ }^{o s}$ a V.A. para q quede cerciorado de todo. $\mathrm{Nr} \mathrm{Sr} \mathrm{Ge}$ a V.A. \&Ynqq ${ }^{\mathrm{n}}$ de Corte a 25 de Sep de $1751^{71}$.

70 Comunicación de Tribunal de Corte de Madrid al Consejo de la Inquisición, de 11 de septiembre de 1751, en la causa abierta contra Francisco Román (AHN, Inquisición, leg. 2519, carp. 4).

71 Comunicación de Tribunal de Corte de Madrid al Consejo de la Inquisición, de 25 de septiembre de 1751, en la causa abierta contra Francisco Román (AHN, Inquisición, leg. 2519, núm. 4). 